\title{
An analysis of certain fields of interventional drug trials registered with Clinical Trials Registry - India
}

\author{
Mounika Pillamarapu \\ Institute of Bioinformatics and Applied Biotechnology \\ Abhilash Mohan \\ Institute of Bioinformatics and Applied Biotechnology \\ Gayatri Saberwal ( $\sim$ gayatri@ibab.ac.in ) \\ Institute of Bioinformatics and Applied Biotechnology https://orcid.org/0000-0003-2410-1431
}

Research article

Keywords: clinical trials, CTRI, India, sites of studies, ethics, primary sponsors, phase of trials, multi-country trials

Posted Date: September 12th, 2019

DOI: https://doi.org/10.21203/rs.2.14370/v1

License: (c) (i) This work is licensed under a Creative Commons Attribution 4.0 International License. Read Full License 


\section{Abstract}

Background There has been a significant increase in the number of trials registered with Clinical Trials Registry - India (CTRI) recently. We therefore wished to understand the current landscape of interventional, drug trials that have run in India. Methods We downloaded all trial records on 4 April 2018, and queried the data after it was formatted into an SQLite database. We distinguished trials hosted by India (India-only trials) and those co-hosted by India and other countries (India-etc trials). Results We analyzed eight fields of data, with the following key results: (a) Year of registration: The India-etc set suffered a serious dip in 2013. Both sets increased sharply in 2017. (b) Phase: Phase 3 trials were the most common in both sets of data, but were manifold more common in the India-etc set. 30\% of the Indiaonly trials had no phase information. (c) Trial sites: Four states each account for $50 \%$ or more of the sites in both sets of data. Also, 7-8 cities accounted for $50 \%$ or more sites in both sets. (d) Ethics committees: Over $70 \%$ of India-only trials had a single ethics committee, but the India-etc trials had a much greater spread. For each set, the maximum exceeded 60 committees per trial. (e) Principal Investigator (PI): $84 \%$ and $73 \%$ of Pls in the India-only and India-etc sets, respectively, had run a single trial each. One PI had run as many as 44 trials. (f) Primary sponsors: global pharma companies sponsored less than $5 \%$ of the India-only set but $92 \%$ of the India-etc set. (g) Fraction of subjects from India in India-etc trials: An abnormally large fraction of participants are not recruited from India. (h) Countries co-hosting the India-etc trials: The pattern was similar to that found for international trials co-hosted by Australia. Conclusions It is important to understand the landscape of trials being run in any country, to understand the recent past, in case of any red flags, and to serve as inputs to changes in policy. The data also serves as a baseline for the future, to ascertain the impacts of new policies, locally or globally.

\section{Introduction}

Since the year 2000, there has been an increase in the number of clinical trial registries around the world, and today there are dozens of them [1]. ClinicalTrials.gov, of the United States of America (US), hosts the largest number of trials, by far. Other prominent publicly accessible registries include the Australia and New Zealand Clinical Trial Registry (ANZCTR), the Chinese Clinical Trial Registry (ChiCTR), Clinical Trials Registry - India (CTRI), and the European Clinical Trials Database (EudraCT). The World Health Organization's International Clinical Trials Registry Platform (ICTRP) is a platform that links to almost 20 registries. Some companies also have their own registries, including the publicly searchable ones of Bayer, Merck and Pfizer.

CTRI was established in July 2007. Although initially voluntary, in June 2009 it became mandatory to register trials running wholly or partially in India. Prospective registration became mandatory from 1 April 2018. Although the number of trials registered with CTRI was low to begin with, with 29 and 155 in 2008 and 2009, respectively [2], this number has grown rapidly in recent years. There were 8,969 registered trials on 30 June 2017 and 12,673 on 4 April 2018 [3]. The number stood at 19,074 on 13 May 2019 [3].

Over the years, several researchers have either summarized data hosted by CTRI or posed particular questions of the registered trials. Examples include an analysis of (i) the year-wise distribution of registrations [4]; (ii) the phase-wise distribution of studies [5-7]; (iii) the regions of the country in which studies have been carried out [4, 5, 7, 8]; (iv) the conditions for which trials were conducted [4, 5, 8, 9]; (v) the categories of the sponsors [5, 8-11]; (vi) whether surrogate end points were assessed more frequently in company-sponsored trials [9]; (vii) whether trial methods were better described in CTRI records than in the subsequent publications [12]; and (viii) what fraction of trials were placebo controlled [11]. Researchers have also pointed out various lacunae in the records, such as (i) non-reporting of sample size; (ii) non-reporting of informed consent from minor trial participants; and (iii) inadequate reporting of post-trial obligations [9].

Although various analyses have been undertaken in the past, given the rapid increase in registrations in recent years, we wished to carry out a more up-to-date analysis of some of the fields of interventional, drug trials. We report these analyses here.

\section{Methodology}

On 4 April 2018 we downloaded all 12,673 trial records then hosted by CTRI, and available at http://ctri.nic.in/Clinicaltrials/advancesearchmain.php. The details of each trial are in an HTML file. We wrote a script in Python (Additional File 1, available at https://osf.io/5zc6f/), which was used to scrape the data, as well as parse it into an SQLite database (available as Additional File 2 at https://osf.io/5zc6f/). The schema of this database is provided in Additional File 3. The expanded methods, that is the (i) SQL commands, (ii) Python scripts and (iii) excel commands used to generate the data in various sheets of Additional Files 5-17, are available in Additional File 4. The data underlying each result was generated by one author, and double checked by another. 
All field names, mentioned below, are italicized.

In the Type of Study field, there was a large number of categories. We chose to focus on the 2,732 (22\%) 'Drug' studies. In terms of the Countries of Recruitment field, these studies fell into three categories, as follows: trials conducted only in India (India-only trials), those conducted both in India and elsewhere (India-etc trials) and those conducted only in other countries (foreign trials). There were 2,070 $(76 \%), 640(23 \%)$ and $22(1 \%)$ trials in these three sets, respectively. However there were internal discrepancies in some of the records and therefore it was not enough to merely look at Countries of Recruitment to determine which country a given trial had run in. For this, one also had to examine the fields (i) Recruitment Status of Trial (Global), (ii) Recruitment Status of Trial (India), (iii) Date of First Enrollment (Global), (iv) Date of First Enrollment (India), (v) Total Sample Size and (vi) Sample Size from India. If a trial listed only India as a Country of Recruitment, but listed anything other than 'Not applicable' for Recruitment Status of Trial (Global) or Date of First Enrollment (Global), for instance, then the trial could not be classified as an India-only trial, and had to be excluded. After analyzing these multiple fields per trial, and excluding the doubtful cases, the numbers of trials per set were reduced to 1,764, 609 and three for the India-only, India-etc and foreign trial sets, respectively.

We did not investigate the foreign trials further. The India-only and India-etc sets each comprised interventional and post-marketing survey (PMS) studies. The numbers were as follows: 1,655 (94\%) interventional and 109 (6\%) PMS for the India-only set; and 606 (99.5\%) interventional and three (0.5\%) PMS for the India-etc set. We conducted all analyses on the interventional trials.

\section{Results}

\section{Year of registration}

We first examined the Year of Registration (Fig. 2 and Additional File 5). For the India-only subset there was a slow beginning in 2007, a jump in 2009, a steady rise until 2011, followed by an uneven plateau until 2016, with a jump again in 2017 and a drop in 2018. The India-etc started slowly, jumped up in 2009, plateaued until 2012, saw a drastic drop in 2013, and then remained subdued until a large spike in 2017, and a drop in 2018. In both sets, the low figures for 2018 essentially reflected only the first three months' registrations. With both the India-only and the India-etc sets, there was about a two-and-a-half fold increase (from 163 to 392 cases and from 31 to 81 cases, respectively) from 2016 to 2017.

\section{Phase of trial}

Next, we explored the Phase of Trial field (Fig. 3 and Additional File 6). The options for this field were Phase 1, Phase 1/2, Phase 2, Phase 2/3, Phase 3, Phase 3/4, Phase 4, N/A (not available) and PMS.

For the India-only set, Phase 3 trials were the most numerous, with $421(25 \%)$ cases, followed by Phase 4 (386 trials, or $23 \%$ ), Phase 2 $(123,7 \%)$, Phase $1(62,4 \%)$ and Phase $3 / 4(59,4 \%)$ trials. There were also low numbers of PMS studies $(55,3 \%)$, and Phase $2 / 3(37,2 \%)$ and Phase 1/2 (17, 1\%) trials. Notably, there were 495 (30\%) trials for which phase information was N/A.

The India-etc set followed a somewhat different trend. In decreasing order they were Phase 3 (429, 71\%), Phase 2 (102, 17\%) and Phase 4 $(31,5 \%)$ trials. There were also low numbers for Phase $3 / 4(14,2 \%)$, Phase $1 / 2(12,2 \%)$, Phase $2 / 3(9,2 \%)$ and Phase $1(1,0.2 \%)$ trials. Although there were no PMS studies, there were eight (1\%) cases for which phase information was N/A.

\section{Sites of study}

We next looked at Sites of Study (Table 1, Additional File 7 and Additional File 8). For the India-only set, four states accounted for over $50 \%$ of the sites. These were Maharashtra (1,416 trials, or $23 \%)$, Gujarat $(803,13 \%)$, Karnataka $(646,10 \%)$, and Andhra Pradesh (493, $8 \%$ ). Within these states, the cities that accounted for $50 \%$ or more of the trials were, respectively, (i) Pune (403 or 29\%) and Mumbai (391, 28\%); (ii) Ahmadabad (435, 54\%); (iii) Bangalore (407,63\%); and Hyderabad (284, 58\%). A total of 11 states or union territories accounted for $90 \%$ of the trial sites. Aside from the four states listed above, these were Delhi (8\%), Uttar Pradesh (7\%), West Bengal (7\%), Tamil Nadu (6\%), Rajasthan (5\%), Chandigarh (3\%), and Pondicherry (1.5\%).

Table 1. For the 1,655 India-only and the 606 India-etc trials (a) the top states and (b) the top cities in which, cumulatively, $50 \%$ or more of the trials took place. 


\begin{tabular}{|c|c|c|c|c|c|c|c|}
\hline \multicolumn{8}{|l|}{ Table 1(a) } \\
\hline India-only & & & & India-etc & & & \\
\hline State name & Count & $\%$ & Cumulative \% & State name & Count & $\%$ & Cumulative \% \\
\hline Maharashtra & 1416 & 22.7 & 22.7 & Maharashtra & 1459 & 21.8 & 21.8 \\
\hline Gujarat & 803 & 12.9 & 35.5 & Karnataka & 1001 & 15.0 & 36.8 \\
\hline Karnataka & 646 & 10.3 & 45.9 & Andhra Pradesh & 734 & 11.0 & 47.8 \\
\hline Andhra Pradesh & 493 & 7.9 & 53.8 & Tamil Nadu & 612 & 9.2 & 57.0 \\
\hline Overall Total & 6242 & 100 & & Overall total & 6683 & 100 & \\
\hline
\end{tabular}

\begin{tabular}{|c|c|c|c|c|c|c|c|}
\hline \multicolumn{8}{|l|}{ Table 1(b) } \\
\hline India-only & & & & India-etc & & & \\
\hline City name & Count & $\%$ & Cumulative \% & City name & Count & $\%$ & Cumulative \% \\
\hline NCR & 564 & 9.0 & 9.0 & Bangalore & 758 & 11.3 & 11.3 \\
\hline Ahmadabad & 436 & 7.0 & 16.0 & NCR & 614 & 9.2 & 20.5 \\
\hline Mumbai & 424 & 6.8 & 22.8 & Pune & 573 & 8.6 & 29.1 \\
\hline Bangalore & 411 & 6.6 & 29.4 & Hyderabad & 532 & 8.0 & 37.1 \\
\hline Pune & 403 & 6.5 & 35.9 & Mumbai & 431 & 6.4 & 43.5 \\
\hline Kolkata & 390 & 6.2 & 42.1 & Ahmadabad & 387 & 5.8 & 49.3 \\
\hline Hyderabad & 284 & 4.5 & 46.7 & Chennai & 304 & 4.5 & 53.9 \\
\hline Jaipur & 249 & 4.0 & 50.6 & & & & \\
\hline Overwall total & 6242 & 100 & & Overall total & 6683 & 100 & \\
\hline
\end{tabular}

Next, we set aside the state-wise point of view, and looked at the distribution of trial sites among cities and towns (hereafter, cities) directly. The India-only trials were hosted by 164 cities, of which eight accounted for $50 \%$ or more of the sites. These were the National Capital Region, or NCR, (564, or 9\%), Ahmadabad (436, 7\%), Mumbai (424, 7\%), Bangalore (411, 7\%), Pune (403, 7\%), Kolkata (390, 6\%), Hyderabad (284,5\%), and Jaipur (249, 4\%). Except for NCR (which comprises cities from different states), Kolkata and Jaipur, all of these cities belong to the four top-listed states.

For the India-etc set, too, four states accounted for over $50 \%$ of the sites. These were Maharashtra (1,459 trials, or $22 \%)$, Karnataka $(1,001,15 \%)$, Andhra Pradesh (734, 11\%), and Tamil Nadu (612, 9\%). Within these states, the cities that accounted for $50 \%$ or more of the trials were, respectively, (i) Pune (573 or 39\%) and Mumbai (411, 28\%); (ii) Bangalore (749, 75\%), (iii) Hyderabad (532, 73\%), and (iv) Chennai $(304,50 \%)$. A total of 11 states or union territories, including 'null', accounted for $90 \%$ of the trial sites. Aside from the four listed above, these were Gujarat (9\%), Delhi (7\%), Rajasthan (5\%), Uttar Pradesh (4\%), West Bengal (4\%), Null (4\%), and Kerala (3\%).

We then set aside the state-wise point of view, and looked at the distribution of trial sites among cities directly. The India-etc trials were hosted by 121 cities, of which seven accounted for $50 \%$ or more of the sites. These were Bangalore (758, or 11\%), NCR (614, or 9\%), Pune 
(573, 9\%), Hyderabad (532, 8\%), Mumbai (431, 6\%), Ahmadabad (387, 6\%), and Chennai (304, 5\%). Except for NCR and Ahmadabad, all of these cities belong to the four top-listed states.

Coming specifically to the case of Phase 3 trials, the India-only and India-etc sets of trials took place in 130 and 112 cities respectively (Additional File 8). 50\% or more of the trials took place in eight and seven cities, respectively, and the four cosmopolitan cities of Bangalore, Hyderabad, Mumbai, and NCR were on both these lists.

\section{Details of ethics committees}

Trials may have taken place at multiple sites, for which the trialists may have taken approval from multiple ethics committees. Therefore we looked at the Details of Ethics Committee field (Fig. 4 and Additional File 9), and examined how many ethics committees were required to approve a given trial. We noted a maximum of 61 committees for an India-only trial and 66 ethics committees for an India-etc trial. Although the maximum values were broadly similar, the distribution of the number of ethics committees per trial was quite different. For the India-only set, $71 \%$ of the trials had just one committee, whereas for the India-etc set, it was required for just $6 \%$. Finally, whereas the India-only set had 156 (9\%) trials with more than 10 ethics committees, the India-etc set had 227 (38\%).

\section{Details of Principal Investigator}

We went on to ask how many doctors were involved as Principal Investigators (PIs) and which of them had run the most trials. For this, we examined the field Details of Principal Investigator or overall Trial Coordinator (multi-center study) and our findings are reported in Fig. 5 and Additional File 10.

After obtaining the list of Pls, the names were cleaned up by removing prefixes and by accounting for obvious variants of a given name. We then examined the distribution of the number of trials run per PI. A PI was not listed for 90 (5\%) of the India-only set, and 245 (40\%) of the India-etc set. We excluded these trials in the calculations of this section.

There were 1,131 Pls associated with the truncated set of 1,565 India-only trials. Of these, 946 (84\%) Pls had run a single trial. A mere $110(10 \%)$ had run two, and there was a steady decrease in the fraction of Pls who had run more than two trials. Seven Pls had run 10 or more $(10,10,11,13,13,16$ and 39$)$ trials, with a maximum of 39 trials run by a single PI. Four of these seven PIs were affiliated to local pharma companies and three to public hospitals. $75 \%$ of the trials had been run by Pls who had run 1-2 trials each.

There were 180 Pls associated with the truncated set of 361 India-etc trials. Of these, 132 (73\%) Pls had run a single trial. A mere 28 $(16 \%)$ had run two, and there was a steady decrease in the fraction of Pls who had run more than two trials. Four Pls had run 10 or more $(10,21,33$ and 44$)$ trials, with a maximum of 44 trials run by a single PI. All four Pls were affiliated with well known multinational pharma companies. $52 \%$ of the trials had been run by Pls who had run 1-2 trials each.

\section{Details of primary sponsors}

We went on to determine the identity of the primary sponsors of the India-only and India-etc trials, and also the classification of these sponsors. For this, we examined the field Primary Sponsor, and its sub-fields.

We first determined the identity of the primary sponsors of the 1,655 India-only set of trials (Additional File 11). The raw data indicated that there were 965 unique sponsors. However many organizations were represented by variants of their names, and after manually correcting for these errors, there were 580 unique sponsors. The top 10 sponsors were the All India Institute of Medical Sciences, Delhi (4.2\%), the Jawaharlal Institute of Postgraduate Medical Education and Research (3.9\%), Null (3.6\%), the Postgraduate Institute of Medical Education and Research (3.6\%), Ajanta Pharma Limited (3\%), Cadila Healthcare Ltd (2.4\%), the Tata Memorial Center/Tata Memorial Hospital (2.2\%), Cipla (2.1\%), Indican Council of Medical Research (1.9\%), and Christian Medical College, Vellore (1.9\%). These sponsors accounted for $29 \%$ of the trials in this set.

Next we examined the classification of the primary sponsors of this set of trials (Additional File 12). The sponsors fell into 139 categories, including 131 variants of 'Others'. However many organizations were classified in two or more ways. After manually correcting for these errors, we identified 99 categories, include 88 variants of 'Others'. The top five categories were Pharmaceutical

Page 5/20 
industry-Indian (29.4\%), Research institution and hospital (22.2\%), Government medical college (16.3\%), Private medical college (5.7\%), and Pharmaceutical industry-Global (4.6\%).

We went on to determine the identity of the primary sponsors of the 606 India-etc set of trials (Additional File 13). The raw data indicated that there were 272 unique sponsors. However many organizations were represented by variations of their names, and after manually correcting for these errors, there were 178 unique sponsors.

The top 10 sponsors were Novartis Healthcare (11.9\%), Pfizer (7.4\%), Sanofi Synthelabo India (4.5\%), Novo Nordisk (4.0\%), AstraZeneca (3.5\%), Merck Sharp and Dohme (3.3\%), Boehringer Ingelheim Pharmaceuticals (2.6\%) Gilead Sciences (2.3\%), Novo Nordisk India (2.3\%), and GlaxoSmithKline Pharmaceuticals (2.1\%). These sponsors accounted for $44 \%$ of the trials in this set.

We next examined the classification of the primary sponsors of this set of trials (Additional File 14). The sponsors fell into 13 categories, include seven variants of 'Others'. However many organizations were classified in two or more ways. After manually correcting for these errors, we identified 11 categories of sponsors, include five variants of 'Others'. The top five categories were Pharmaceutical industryGlobal (91.7\%), Government funding agency (2.6\%), Pharmaceutical industry-Indian (1.8\%), Research institution (1.2\%), and Research institution and hospital (1.2\%).

In both sets of data, except for sponsors classified as 'Indian' or 'Global', there was no separate identification of whether an organization was foreign or Indian.

\section{Number of subjects from India and elsewhere in India-etc trials}

For the 606 India-etc set of trials we then looked at the fraction of trial participants from India, out of the total for a given trial, phasewise. As mentioned in section 2, Phases 1 (1 trial, or 0.2\%), 2 (102, 17\%), $3(429,71 \%)$ and $4(31,5 \%)$ accounted for $563(93 \%)$ trials (Additional File 15). The remaining 43 (7\%) trials comprised phases 3/4, 1/2, 2/3 and N/A trials, which we did not investigate.

Within Phases 1, 2, 3 and 4, separately we examined the planned recruitment from India, as a fraction of the total recruitment. The data was binned as follows: $0-20 \%, 21-40 \%, 41-60 \%, 61-80 \%$ and $81-100 \%$ (Fig. 6 and Additional File 15). There was only one Phase 1 trial, and this was in the $0-20 \%$ bin. For the Phase $2-4$ trials, most did not exceed $40 \%$, and for each of these phases, less than $10 \%$ of the trials exceeded $60 \%$.

Overall, the planned recruitment from India exceeded $60 \%$ of the total in 29 trials. The break-up was 10,17 and two trials in Phases 2,3 and 4 respectively. An examination of the sponsors of these trials shows that in Phases 2, 3 and 4, 4 (40\%), $3(17.6 \%)$ and zero (0\%) trials, respectively, were sponsored by Indian, or Indian-origin, companies (Additional File 15). Two trials (one each in Phases 2 and 3 ) were sponsored by foreign non-profits.

We went on to examine the planned versus actual recruitment from India (Additional File 16). Out of 606 trials, for 310 (51\%) this calculation could not be done because they were neither completed nor terminated. Further, for $281(46 \%)$ trials, the CTRI records were not updated with the final numbers. For $13(2 \%)$ trials, both the planned and final numbers were available. In most of these cases, the two numbers were similar. However, in one case the fraction from India jumped from 10\% (planned) to 100\% (actual), and in another from $60 \%$ to $80 \%$.

\section{Details of the countries co-hosting the India-etc trials}

By definition, the India-etc trials took place in India and one or more other countries. We identified the top 10 co-host countries of these trials (Additional File 17): USA (co-hosted 65\% of the trials), Russian Federation (49\%), Germany (48\%), Canada (46\%), Poland (43\%), Spain $(42 \%)$, UK (41\%), Italy (39\%), France (38\%) and Hungary (36\%). We also examined the distribution of how many countries were involved per trial. $9 \%$ of the trials ran in two countries, $17 \%$ in $3-5,19 \%$ in $6-10,14 \%$ in $11-15$, and $42 \%$ in more than 15 countries (Fig. 7 and Additional File 17).

\section{Discussion}

Here, we first discuss each section separately, before summarizing the key results.

\section{Year of registration}

Page 6/20 
An analysis of the year-wise registration of trials has been performed by other workers as well [4]. They analyzed the 3,325 trials registered with CTRI up to 2015. In contrast, this study focused on interventional drug trials up to early April 2018, and distinguished the India-only and India-etc subsets of trials. The slow start in 2007 and 2008, followed by a big jump up in 2009 was common to the Chaturvedi et al. study and both our datasets. However the other group observed a strong drop in 2011, which neither of our datasets demonstrated. Also, the strong drop in 2013 observed by Chaturvedi et al. was observed only for our India-only set. These differences can be traced to the different data that was analyzed by the two groups.

CTRI was established only in 2007, and that is the reason for the initial low numbers. In 2009, registration became compulsory [12] and that led to the jump in both the Chaturvedi et al. study, and in both of our datasets. This is similar to the upsurge of trial registrations at ClinicalTrials.gov after the International Committee of Medical Journal Editors announced its requirement that trials be pre-registered if the results were to subsequently be published in their journals [13]. In May 2012, the Parliamentary Standing Committee on Health and Family Welfare severely criticized the office of the Drug Controller General of India (DCGI) [14]. Soon thereafter the government constituted the Prof. Ranjit Roy Chaudhury Expert Committee. The recommendations of this committee [15], and orders of the Supreme Court [16], had a chilling effect on the number of trials being registered, from which the situation recovered only in 2017. As noted above, the reduced activity was significantly more pronounced in the India-etc set. Sponsors that had initiated or planned multi-country trials which included sites in India moved them elsewhere and were slow to look at India again [17]. The notification that from 1 April 2018 trials had to be prospectively registered, would account for the large spike in registrations in 2017.

Separately, in 2009, it was noted that whereas ClinicalTrials.gov listed 700 trials with sites in India, CTRI listed a mere 155 [2], indicating that trials running in India were significantly under-registered with CTRI in the early years of the registry. This is unlikely to be the case now, since, as of early April 2019, there were just 3,661 studies registered with ClinicalTrials.gov that listed India as a country of recruitment, whereas there were 18,353 trials registered with CTRI. Of these, 17,168 (93.5\%) were India-only trials; 1,102 (6\%) India-etc trials; $80(0.4 \%)$ foreign trials; and 3 records did not list any country of recruitment. Given the large increase in the number of trials registered with CTRI in recent years, it is likely that most, if not all, relevant trials currently registered in the US, are also registered with CTRI.

\section{Phase of trial}

In terms of the phases of India-only trials, the largest set - 30\% - concerns N/A cases. This is surprising for interventional drug trials. Only $1 \%$ of the India-etc set did not list the phase, and thus the reporting of the phase of trials running in India appears to be much better for multi-country trials than domestic ones.

For the India-only trials, if we ignore the N/A cases, there was a trend of decreasing numbers of trials in Phases $3,4,2$ and 1 . This was consistent with the previous study of CTRI data referred to above, although in that study the fraction of trials in Phase 3 was about double that in this set, and the totals for trials in Phases 4 and 2 were much closer [4].

The India-etc set had a different trend of decreasing numbers of trials in Phases 3, 2 and 4. Also, Phase 3 trials dominated the India-etc set more emphatically, accounting for $71 \%$ of the trials, in contrast to just $25 \%$ in the India-only set.

For comparison with the Indian scenario, we looked at the trend in two other registries. In Australia, for drug trials over the years 2006 2015, there were decreasing numbers of trials in Phases 3 (39\%), 2 (25\%), 4 (14\%) and 1 (14\%) [18], which parallels that in the India-etc set. An Advanced Search of ClinicalTrials.gov on 6 April 2019, for all interventional trials (excluding those for Expanded Access) that have run in the US, revealed a sequence of Phases $2(29,514), 1(21,650), 3(13,537)$ and $4(7,635)$ in decreasing order.

It is clear that compared to the situation in the Australian and US registries, Phase 1 trials, the phase that includes first-in-human trials, which carry the highest risk, are not abnormally abundant in India. Further, since Phase 3 trials require the largest number of participants, they are often the subject of off-shoring [19]. Therefore it is unsurprising that this phase leads the Indian trials, especially in the India-etc set.

\section{Sites of study}

Trials in India have taken place in a large number of cities, only some of which are highly cosmopolitan. This is relevant to the question of whether or not trials are taking place in representative populations of the entire nation. The above-mentioned $59^{\text {th }}$ Parliamentary Report commented that "In response to a question as to how various ethnic groups are being enrolled in Phase III clinical trials, the Committee was informed that "most trials were taking place in cosmopolitan towns. It is understood that cosmopolitan cities have a

Page $7 / 20$ 
heterogeneous population comprising various ethnic groups. Otherwise there is no proactive, specific procedure to test new drugs on different ethnic groups." [14]. The data above suggests that this response is incorrect. Only 1,683 (27\%) of the India-only and 2,335 (35\%) of the India-etc trials took place in the truly cosmopolitan cities of Bangalore, Hyderabad, Mumbai, and NCR. Even accounting for some people from other states in any given city, it can be safely stated that over $50 \%$ of the trial sites were in less cosmopolitan cities. Since the report specifically discussed Phase 3 trials, we also looked into this subset. Unsurprisingly, the trends were similar.

Further, we note that many trials $(67$, or $1 \%$, for the India-only and 231 , or $4 \%$, for the India-etc sets) did not list the city from which they recruited trial participants. Either the data was not entered, and therefore this is a data quality issue, or it was not registered in a consistent way, and therefore was not downloaded, in which case it is a data formatting issue.

Finally, in order to strengthen the quality of trials, it is important that trial sites be inspected regularly but randomly. Even the US Food and Drug Administration (FDA), which has limited resources to inspect sites, inspected $1.9 \%$ of all domestic sites and $0.7 \%$ of all foreign sites in 2008 [20]. The concentration of trials in a few Indian cities indicates that more inspections should happen in these cities. There must also be random inspections of sites in the many other cities that host trials. Health activists have stated that currently hardly any inspections happen [21]. If so, the situation must improve, and if regional offices for inspections are set up, it would be prudent to set them up in cities or states which host the largest number of trials.

\section{Details of ethics committees}

We turn to the distribution of numbers of ethics committees per trial. These numbers are merely a reflection of the large number of sites at which trials are running. Our results show that whereas most India-only trials require only one ethics committee, the India-etc trials tend to require more. We have separately shown that most India-etc trials are sponsored by multinational pharma companies. Since it has been asserted that drug-marketing is part of drug-testing, and vice versa, the larger number of sites per trial for India-etc compared to the India-only trials might reflect the marketing efforts of the multinational companies.

Be that as it may, the large number of ethics committees per trial seems to be impractical, given the fact that various problems have been noted with the functioning of these committees in India. Documented examples of such problems include (a) only three of 11 committee members attended a meeting; (b) on average it took 90 seconds to approve a proposal; (c) a committee member was removed for not approving a trial [19] and (d) clinical experts, including those from prestigious public and charitable institutions, colluded with companies to fake letters to the regulator [14]. As such, it is possible that some approvals were obtained in a less-than-authentic manner, in which case the large number of committees per trial is something of a charade. Instead, it might be advisable to have a single, high quality ethics committee per trial. The pros and cons of a single ethics committee for a multi-site trial have been debated elsewhere [22, 23]. Both the US and the European Union (EU) have taken steps to address this issue, although their concerns have been different, and relate to the fact that the approval of a trial by multiple ethics committees slows down the trial. In the US, in 2016, the National Institutes of Health $(\mathrm{NIH})$ issued a new policy that required multisite trials, if funded by the $\mathrm{NIH}$, to use a single Institutional Review Board (IRB). Following this, in 2017, the NIH's National Center for Advancing Translational Sciences (NCATS) created the NCATS Streamlined, Multisite, Accelerated Resources for Trials (SMART) IRB Platform to facilitate this [24]. And under the Final Rule announced in the US in 2017, cooperative, multi-institutional trials, usually require only one ethics committee's approval [25]. In the EU, a recent regulation also usually requires clearance by a single committee regardless of how many countries the trial is running in [26].

\section{Details of Principal Investigator}

In 2011, it was noted with concern that there was a PI who had run as many as 25 trials in India [27]. And in 2016 it was noted that a clinician had simultaneously run 10-15 trials in the country [28]. In our analysis, one PI in the India-only set (who had run 39 trials) and two in the India-etc set (33 and 44 trials, respectively) had exceeded the number 25, although it is not known how many of these trials ran simultaneously. One needs to be concerned about a given PI running many trials in India. It is known that the specialist:patient ratio in India is poor [28], and it is also widely acknowledged that the workload on Indian doctors can be extremely heavy. This gives rise to the apprehension that a doctor may not be able to take adequate care of the participants in multiple trials. Although all of these Pls may have run their trials perfectly, any plan to audit trials in India should include such cases.

\section{Details of primary sponsors}

In terms of the nature of the primary sponsor of the India-only trials, certain public sector hospitals had sponsored the maximum number of trials. However, overall, the local pharma industry was the biggest sponsor and the global pharma industry sponsored less than $5 \%$. Of concern, almost $4 \%$ of the trials did not list a sponsor. Also, due to variations in the name of a given sponsor, manual cleaning reduced

Page $8 / 20$ 
the number of sponsors by one-third. Names need to be entered in a uniform way, to provide for automated analyses of the sponsors of thousands of trials.

In terms of the nature of the primary sponsor of the India-etc trials, the top 10 sponsors were well known multinational pharma companies, which are known to be among the top sponsors of trials [29]. This is also unsurprising given the increasing off-shoring of trials to developing countries in recent years [19]. However we have three concerns regarding the data, as follows: (a) in one case, the World Health Organization was classified as a Government funding agency. There probably needs to be a separate category for such organizations, which should not be clubbed with funding agencies of state governments or the Government of India. (b) A large Indian pharma company was classified as Pharmaceutical industry-Global. Whereas it is true that the company has become a global company, it is an Indian-origin company, which became a global company only in recent years. Perhaps some distinction should be made between such Indian-origin, global companies and multinational companies based abroad. (c) the variants in sponsor names or classification necessitate significant manual cleaning of the data. It would be better if CTRI had a more uniform method of recording each sponsor's name or category.

\section{Number of subjects from India and elsewhere in India-etc trials}

We went on to examine the fraction of trial participants from India out of the total number of participants for a given India-etc trial, phase-wise. There have been apprehensions about people in developing countries being used as guinea pigs for trials planned by organizations in the developed world [27, 30,31]. However, in terms of the fraction of participants from India in global trials, the results were reassuring, since most trials recruited less than $40 \%$ of participants from India. As such, an abnormally large number of participants were not planned to be recruited from India. Furthermore, seven (24\%) of the 29 trials, for which the planned recruitment from India exceeded 60\%, were sponsored by Indian companies, and therefore the high percentage was unsurprising. Nevertheless, there is another angle we need to examine. There have been cases in the past where about half the recruits in an international trial were planned to be recruited from India, but in fact more than $80 \%$ were [27]. We identified one case where indeed there was a sharp increase from planned to actual recruitment from India. However, for almost half the trials, the records had not been updated with actual recruitment, and therefore there was no way to determine whether this phenomenon was common or not. The outdated records are cause for concern.

\section{Details of the countries co-hosting the India-etc trials}

We went on to examine the foreign locations for the India-etc trials. Of the top 10 countries which co-hosted trials with India, eight countries overlapped the top ten countries which co-hosted interventional trials with Australia [18]. And since one of the top 10 countries in the Australian list was its neighbor New Zealand, it is unsurprising that the latter country was not a top co-host of trials in India. Similarly, five of the top six co-host countries for the India-etc trials overlapped the top seven countries for international trials that tested a drug or biological and were registered with ClinicalTrials.gov [32]. As such, the pattern of countries co-hosting trials with India was similar to that noted in Western nations.

In terms of the distribution of the number of countries per trial of the India-etc trials, we can compare the figures with those in two other reports. (a) One study examined global trends of interventional trials registered with ClinicalTrials.gov, and compared the distribution of the number of countries involved per trial in the time periods 1999-2003 and 2009-2013 [33]. Over the two time periods, there was a large reduction in the number of trials that ran in just two countries, and a significant increase in the number that ran in six or more nations. In the period 2009-2013, approximately 33\%, $16 \%, 16 \%$ and $33 \%$ of the 6,000 trials ran in two, 3-5, $6-10$ and over 10 countries, respectively. Of the 606 multi-country trials that ran in India, only $9 \%$ involved two countries and $56 \%$ involved 10 or more countries. (b) Another study, mentioned above, looked at international trials that took place in Australia from 2006-2015 [18]. Here the authors compared the interventional trials registered with ClinicalTrials.gov with those registered with ANZCTR. The 3,013 multi-country trials registered with ClinicalTrials.gov had a pattern closer to the Indian one, since $9 \%, 8 \%, 15 \%, 21 \%$ and $47 \%$ of the trials ran in two, three, $4-$ 6, 7-11 and over 11 countries, respectively. However the 470 multi-country trials registered with ANZCTR had a different pattern, since $58 \%, 10 \%, 16 \%, 9 \%$ and $8 \%$ trials ran in two, three, 4-6, 7-11 and over 11 countries, respectively. The trials registered with ClinicalTrials.gov were more likely to be drug trials than those registered with ANZCTR, and this may explain the different patterns.

There are many problems with how trials are run in India [14, 28, 34], but on the face of it, for trials being co-hosted by India and one or more other countries, the identity of co-host countries, and the pattern of co-hosting trials is similar to that of a major Western nation, that is Australia.

\section{Summary}

Page 9/20 
In this paper we have only analyzed data provided in the records at CTRI. We have not looked into other important issues such as the quality of clinical trial infrastructure, the general lack of high quality healthcare that drives many of the participants to trials, or the posttrial availability of test drugs [35], for instance. We have focused on two sets of interventional, drug trials run in India, that is those that have run only in India, the India-only set, and those that have also run elsewhere, the India-etc set. We analyzed eight fields of data, and the data sometimes showed different patterns in these two sets. Our findings, in brief, were as follows:

(i) In terms of the year of registration, only the India-etc set suffered a (serious) dip in 2013. Both sets increased sharply in 2017.

(ii) In terms of the phase of the drug trials, in decreasing order, the frequencies were Phases 3, 4, 2 and 1 for the India-only set and Phases $3,2,4$ and 1 for the India-etc set, with $3 \%$ or less for Phases $1 / 2,2 / 3$ and $3 / 4$ in each of the two data sets. Notably, (a) Phase 3 trials were manifold more common in the India-etc set, and (b) there was no phase information for $30 \%$ of the India-only trials.

(iii) Four states account for $50 \%$ or more of the trials in both sets of data, with three states common to the two lists. The India-only and India-etc sets of trials ran in 164 and 121 cities, respectively. Eight and seven cities, respectively, accounted for $50 \%$ or more of the trials in these two sets, with six of the cities common to the two lists.

(iv) Whereas the maximum number of ethics committees for a given trial was quite close, at 61 for the India-only and 66 for the India-etc sets, the distribution of numbers of ethics committees per trial was very different in the two sets. Thus, whereas $71 \%$ of the India-only trials had one committee, $6 \%$ of the India-etc did so.

(v) In terms of the names of PIs, the India-only set were much better at reporting this data than the India-etc set, with names going unreported for $5 \%$ and $40 \%$ of the two sets, respectively. Also, whereas $84 \%$ of Pls of India-only trials had run just one trial, $73 \%$ of those in India-etc trials had done so. Seven and four Pls in these two sets, respectively, had run 10 or more trials each.

(vi) Primary sponsors: In the India-only set, Indian pharma companies sponsored the largest number (29\%) of trials, whereas the global pharma companies sponsored less than $5 \%$. In the India-etc set, $92 \%$ of the sponsors were global pharma companies.

(vii) For most India-etc trials, the planned recruitment from India did not exceed $40 \%$ of the total participants. However for most trials there are no records of what the actual recruitment was, and these incomplete records are cause for concern.

(viii) The countries co-hosting trials with India, and the distribution of number of countries per trial, was similar to that found for most international trials co-hosted by Australia.

Finally, we note that the study has some limitations, as follows: (a) we have analyzed only a fraction of the interventional, drug trials registered with CTRI as of April 2018. (b) we have analyzed only eight facets of the data concerning these trials. A comprehensive understanding of the data hosted by CTRI would require many more analyses. And (c) our analysis cannot attest to the validity of the inputted data.

\section{Conclusion}

As of 1 April 2018, CTRI made it mandatory to prospectively register trials run in India. This has led to an enormous increase in the number of registered trials, and will continue to give a boost to the accountability of the clinical trial enterprise in the country. It is important to understand the landscape of trials being run in any country, to understand its recent past, to identify any red flags, and to serve as inputs to changes in policy. The data also serves as a baseline for the future, to ascertain the impact of new policies, locally or globally.

\section{Abbreviations}

ANZCTR: Australian New Zealand Clinical Trial Registry; BA/BE: Bioavailability or bioequivalence studies; CTRI: Clinical Trials Registry India; DCGI: Drug Controller General of India; EU: European Union; FDA: Food and Drug Administration; Foreign trials: Trials conducted only in other countries; India-etc trials: Trials conducted in India and also elsewhere; India-only trials: Trials conducted only in India; IRB: Institutional review board; N/A: Not available; NCATS: National Center for Advancing Translational Sciences; NCR: National capital region; $\mathrm{NIH}$ : National Institutes of Health; Pl: Principal investigator; US: United States of America.

\section{Declarations}




\section{Acknowledgments}

We thank Dr. Jogin Desai for feedback.

\section{Funding}

This work was supported by intra-mural funding of the Institute of Bioinformatics and Applied

Biotechnology, which is funded by the Department of IT, BT and S\&T of the Government of Karnataka. The funder played no role in the study, including in the design; in the collection, analysis or interpretation of the data; in the preparation of the manuscript; or in the decision of where to publish.

Availability of data and materials

Additional Files 1 and 2 are available from the the OSF database repository at https://osf.io/5zc6f/. All other data generated or analysed during this work is included in this article, and its additional files.

\section{Authors' contributions}

GS conceptualized the study, acquired funding for the study, and supervized the project. AM and PM wrote programmes to process the data. PM analyzed the data. AM and GS validated the data analysis. GS wrote the first draft of the manuscript, and all authors provided inputs to subsequent drafts. All authors read and approved the final manuscript.

\section{Ethics approval and consent to participate}

Not applicable

\section{Consent for publication}

Not applicable

\section{Competing interests}

The authors declare that they have no competing interests.

\section{References}

1. Fleminger J, Goldacre B. Prevalence of clinical trial status discrepancies: A cross-sectional study of 10,492 trials registered on both ClinicalTrials.gov and the European Union Clinical Trials Register. PLoS One. 2018;13:e0193088.

2. Tharyan P. Prospective registration of clinical trials in India: Strategies, achievements and challenges. J Evid Based Med. 2009;2:1928.

3. http://ctri.nic.in. Accessed 30 Jun 2017, 4 Apr 2018, 7 Apr 2019, and 13 May 2019.

4. Chaturvedi M, Gogtay NJ, Thatte UM. Do clinical trials conducted in India match its healthcare needs? An audit of the Clinical Trials Registry of India. Perspect Clin Res 2017;8:172-5.

5. Ravindran D, Nikarge S. Clinical Trials Watch. Indian J Med Ethics. 2010;7:127-9.

6. Ravindran D. Clinical Trials Watch. Indian J Med Ethics. 2013;10:73.

7. Bhide SS, Tadavi FM, Maurya MR, Bhojne SK, Chandrakar P. Assessment of clinical trials registered at clinical trial registry of India over past decade: an audit. Int J Clin Trials. 2016;3:238-43.

8. Nikarge S, Pamnani D. Clinical Trials Watch. Indian J Med Ethics. 2009;6:228-31.

9. Yadav P, Jaykaran, Chaudhari M, Saxena D, Kantharia ND. Clinical trials registered in clinical trial registry of India: A survey. J Pharmacol Pharmacother. 2011;2:289-92 
10. Jacob VD, Ravindran D, Ved K. Clinical Trials Watch. Indian J Med Ethics. 2012;9:73.

11. Circle of Medicines: Development to Access. Study on accessibility and affordability of medicines that underwent trials in India. SAMA - Resource Group for Women and Health. 2016. http://www.samawomenshealth.in/circle-of-medicinesdevelopment-toaccess. Accessed 13 May 2019.

12. Tharyan P, George AT, Kirubakaran R, Barnabas JP. Reporting of methods was better in the Clinical Trial Registry-India than in Indian journal publications. J Clin Epidemiol. 2013;66:10-22.

13. Zarin DA, Ide NC, Tse T, Harlan WR, West JC, Lindberg DA.Issues in the Registration of Clinical Trials. JAMA. 2007;297:2112-

14. Department-related Parliamentary Standing Committee on Health and Family Welfare. Fifty-ninth report on the functioning of the Central Drugs Standard Control Organisation (CDSCO). Rajya Sabha Secretariat, New Delhi; 2012 May.

http://164.100.47.5/newcommittee/reports/EnglishCommittees/Committee\%20on\%20Health\%20and\%20Family\%20Welfare/59.pdf. Accessed 13 May 2019.

15. Actions on the recommendations of Prof. Ranjit Roy Chaudhury expert committee to formulate policy and guidelines for approval of new drugs, clinical trials and banning of drugs.2013. http://www.sgpgi.ac.in/sop/Action_RR_Choudhury_Committee_06.11.2013.pdf. Accessed 13 May 2019.

16. Ilancheran Measuring The Impact Of Reforms On India's Clinical Trial Environment. 2017. https://www.clinicalleader.com/doc/measuring-the-impact-of-reforms-on-india-s-clinical-trial-environment-0001. Accessed 13 May 2019.

17. Reardon S. NIH makes wary return to India. Nature 2014;506:143-4.

18. Askie LM, Hunter KE, Berber S, Langford A, Tan-Koay AG, Vu T, et al. The clinical trial landscape in Australia 2006- Sydney: Australian New Zealand Clinical Trial Registry 2017. http://anzctr.org.au/docs/ClinicalTrialsInAustralia2006-2015.pdf. Accessed 13 May 2019.

19. Huijstee MV, Schipper I eds. Putting Contract Research Organization on the Radar. An exploratory study on outsourcing of clinical trials to contract research organization in non-traditional trial regions. Amsterdam, the Netherlands: SOMO Centre for Research on Multinational Corporationshttps://www.somo.nl/wpcontent/uploads/2011/02/Putting-Contract-Research-Organisations-on-theRadar.pdf. Accessed 13 May 2019.

20. Ayalew K. FDA Perspective on International Clinical Trials. 2013.

https://www.fda.gov/downloads/training/clinicalinvestigatortrainingcourse/ucm378499.pdf. Accessed 13 May 2019.

21. Shelar J. After a lull of five years, clinical trials on the rise in India. 2018. https://www.thehindu.com/news/national/after-a-lull-offive-years-clinical-trials-on-the-rise-in-india/article24069487.ece. Accessed 13 May 2019.

22. Menikoff J. The Paradoxical Problem with Multiple-IRB Review. N Engl J Med. 2010;363: 1591-

23. Klitzman R. How local IRBs view central IRBs in the US. BMC Med Ethics. 2011;12:13-

24. Life Science Daily News Desk. NIH streamlines ethics review of multisite clinical trials. 2017. https://lifesciencedaily.com/stories/20771-nih-streamlines-ethics-review-multisite-clinical-trials/. Accessed 13 May 2019.

25. Breuer JR, Berman EM, Fosheim GE. Clinical Research (R)evolution - Updating the "Common Rule" for the Modern Era. 2017. https://www.drinkerbiddle.com/insights/publications/2017/02/clinical-research-revolution. Accessed 13 May 2019.

26. Rea G. The long-awaited EU clinical trial regulation. 2018. https://www.irishlegal.com/article/gillian-rea-the-long-awaited-eu-clinicaltrial-regulation. Accessed 13 May 2019.

27. Pandey A, Aggarwal A, Seth SD, Malik Mohua, Juneja A. Strengthening ethics in clinical research. Indian J Med Res. 2011;133:339-

28. Bahri C. India's changing clinical trials scene. Lancet. 2016;388:2727-8.

Page $12 / 20$ 
29. Keezhupalat SM, Naik A, Gupta S, Srivatsan R, Saberwal G. An Analysis of Sponsors/Collaborators of 69,160 Drug Trials Registered with ClinicalTrials.gov. PLoS One.2016;2:e0149416.

30. Glickman SW, McHutchison JG, Peterson ED, Cairns CB, Harrington RA, Califf RM, et al. Ethical and Scientific Implications of the Globalization of Clinical Research. N Engl J Med. 2009;360:816-23.

31. Weigmann K. The ethics of global clinical trials. EMBO reports. 2015;16:566-70.

32. Hoekman J, Frenken K, Zeeuw DD, Heerspink HL. The Geographical distribution of Leadership in Globalized Clinical Trials. PLoS One. 2012;7:e45984.

33. Hsiehchen D, Espinoza M, Hsieh A. The Cooperative Landscape of Multinational Clinical Trials. PLoS One. 2015;10:e0130930.

34. Nundy S, Gulhati CM. A new colonialism? - Conducting clinical trials in India. N Engl J Med. 2005;352:1633-

35. Datta J. Taking the 'fear factor' out of clinical trials. 2017. https://www.thehindubusinessline.com/specials/pulse/taking-the-fearfactor-out-of-clinical-trials/article9696025.ece. Accessed 13 May 2019.

\section{Additional Files}

Additional File 1. The python script used on the data downloaded from CTRI to create the SQLite database.

Additional File 2. The SQLite database hosting data of the 12,673 CTRI trial records.

Additional File 3. The schema of the SQLite database.

Additional File 4. Expanded methods. The (i) SQL commands, (ii) Python scripts and (iii) excel commands used to generate the data in various sheets of Additional Files 5-17.

Additional File 5. For the 1,655 India-only and the 606 India-etc trials (a) the number of trials registered each year from 2007 to early April 2018; and (b) the percentage of trials each year as a fraction of all the trials during this period.

Additional File 6. For the 1,655 India-only and the 606 India-etc trials (a) the number of trials in each phase, (b) the percentage of trials in each phase as a fraction of all the trials and (c) the cumulative percentage of trials in all the phases.

Additional File 7. Sites of study

\section{The 1,655 India-only trials}

7.1a_The frequency with which the 1,655 India-only trials took place in each state.

7.1b_The frequency with which the India-only trials took place in each city of the four top states. These four states cumulatively hosted over $50 \%$ of the India-only trials.

7.1c_The frequency with which the India-only trials took place in various cities of the country.

7.1d_The clubbing of names of cities hosting India-only trials (i) if they refer to the same city, or (ii) if they constitute the National Capital Region (NCR).

7.1e_The frequency with which the India-only trials took place in various cities of the country after clubbing names (i) which refer to the same city, or (ii) that constitute the National Capital Region (NCR).

\section{The 606 India-etc trials}

7.2a_The frequency with which the 1,655 India-only trials took place in each state.

7.2b_The frequency with which the India-only trials took place in each city of the four top states. These four states cumulatively hosted over $50 \%$ of the India-only trials.

7.2c_The frequency with which the India-only trials took place in various cities of the country. 
7.2d_The clubbing of names of cities hosting India-only trials (i) if they refer to the same city, or (ii) if they constitute the National Capital Region (NCR).

7.2e_The frequency with which the India-only trials took place in various cities of the country after clubbing names (i) which refer to the same city, or (ii) that constitute the National Capital Region (NCR).

Additional File 8. The Phase 3 India-only trials and India-etc trials.

\section{The Phase 3 India-only trials.}

8.1a_The frequency with which the Phase 3 India-only trials took place in various cities of the country.

8.1b_The clubbing of names of cities hosting Phase 3 India-only trials (i) if they refer to the same city, or (ii) if they constitute the National Capital Region (NCR).

8.1c_The frequency with which the Phase 3 India-only trials took place in various cities of the country after clubbing names (i) which refer to the same city, or (ii) that constitute the National Capital Region (NCR).

\section{The Phase 3 India-etc trials}

8.2a_The frequency with which the Phase 3 India-etc trials took place in various cities of the country.

8.2b_The clubbing of names of cities hosting Phase 3 India-etc trials (i) if they refer to the same city, or (ii) if they constitute the National Capital Region (NCR).

8.2c_The frequency with which the Phase 3 India-etc trials took place in various cities of the country after clubbing names (i) which refer to the same city, or (ii) that constitute the National Capital Region (NCR).

Additional File 9. The ethics committees per trial: the number, percentage and cumulative percentage, for

9a_the 1,655 India-only,

9b_the 606 India-etc trials,

9c_for both the India-only and the India-etc trials, summarized.

Additional File 10. Number of trials per PI

\section{For the 1,655 India-only trials:}

10.1a_The number of trials run by each PI (raw data).

10.1b_The sets of names that were clubbed after the prefixes were removed.

10.1c_The names of PIs, in decreasing order of the number of trials conducted, after clubbing. 
10.1d_(i) The frequency distribution of the number of PIs for (a) the different number of trials per PI; (b) in percentage and (c) in cumulative percentage. (ii) The frequency distribution of (a) the total number of trials run by PIs running different numbers of trials, (b) in percentage and (c) in cumulative percentage.

\section{For the 606 India-etc trials:}

10.2a_The number of trials run by each PI (raw data).

10.2b_The sets of names that were clubbed after the prefixes were removed.

10.2c_The names of Pls, in decreasing order of the number of trials conducted, after clubbing.

10.2d_(i) The frequency distribution of the number of Pls for (a) the different number of trials per Pl; (b) in percentage and (c) in cumulative percentage. (ii) The frequency distribution of (a) the total number of trials run by Pls running different numbers of trials, (b) in percentage and (c) in cumulative percentage.

10.3 For the India-only and India-etc trials, (i) the names of Pls who conducted 10 or more trials, (ii) the numbers of trials per PI and (iii) the affiliations of the Pls.

Additional File 11. The primary sponsors of the 1,655 India-only trials.

11a. Raw data of the name, type and address of the sponsor of each trial.

11b. The frequency of occurrence of each sponsor name using the raw data.

11c. The manually identifed names that refer to the same organization.

11d. The corrected frequency of occurrence of each sponsor name after manually determining which names refer to the same organization.

Additional File 12. The classification of the sponsors of the 1,655 India-only trials.

12a. Raw data of the name, type and address of the sponsor of each trial.

12b. The frequency of occurrence of each sponsor type using the raw data.

12c. Identification of discrepancies in the classification of a given sponsor over various trials.

12d. The statistics of discrepancies in sponsor classification.

12e. Re-integrating the corrected sponsor type in the discrepant cases.

12f. The frequency of different categories of primary sponsors, based on the manually corrected data.

Additional File 13. The primary sponsors of the 606 India-etc trials.

13a. Raw data of the name, type and address of the sponsor of each trial.

13b. The frequency of occurrence of each sponsor name using the raw data

13c. The manually identifed names that refer to the same organization.

$13 \mathrm{~d}$. The corrected frequency of occurrence of each sponsor name after manually determining which names refer to the same organization.

Additional File 14. The classification of the sponsors of the 606 India-etc trials. 
14a. Raw data of the name, type and address of the sponsor of each trial.

14b. The frequency of occurrence of each sponsor type using the raw data.

14c. Identification of discrepancies in the classification of a given sponsor over various trials.

14d. The statistics of discrepancies in sponsor classification.

14e. Re-integrating the corrected sponsor type in the discrepant cases.

14f. The frequency of different categories of primary sponsors, based on the manually corrected data.

Additional File 15. Planned enrollment from India in the 606 India-etc trials.

15a. The total sample size, sample size from India, and percentage from India for all 606 trials.

15b. The total sample size, sample size from India, and percentage from India for the Phase 1 trial.

15c. The total sample size, sample size from India, and percentage from India for the Phase 2 trials.

15d. The total sample size, sample size from India, and percentage from India for the Phase 3 trials

15e. The total sample size, sample size from India, and percentage from India for the Phase 4 trials.

15f. The phase of the trial, the percentage of recruitment from India, the condition and the primary sponsor of trials with $60 \%$ or more planned recruitment from India.

$15 \mathrm{~g}$ Summary statistics of the phase-wise planned enrollment from India in the India-etc trials. (i) The number of trials (and their percentage of the total) in Phases 1, 2, 3 and 4; (ii) For Phases 1, 2, 3 and 4, the number of participants in each phase, in 5 bins; and (iii) The data in (ii) expressed as a percentage of the total number of trials in that phase.

Additional File 16. Planned versus final enrollment from India in the 606 India-etc trials. For the planned enrollment we list the total sample size, sample size from India and fraction from India. For the final enrollment, we list final enrollment numbers achieved (total), final enrollment numbers achieved (India) and fraction from India.

Additional File 17. For the 606 India-etc trials, the list of countries that co-hosted each trial.

17a. The names of the countries that co-hosted each of the 606 India-etc trials, and their count.

17b. The frequency distribution of the number of countries that were co-hosts of the 606 India-etc trials.

17c. The frequency distribution of particular countries that were co-hosts of the 606 India-etc trials.

\section{Figures}




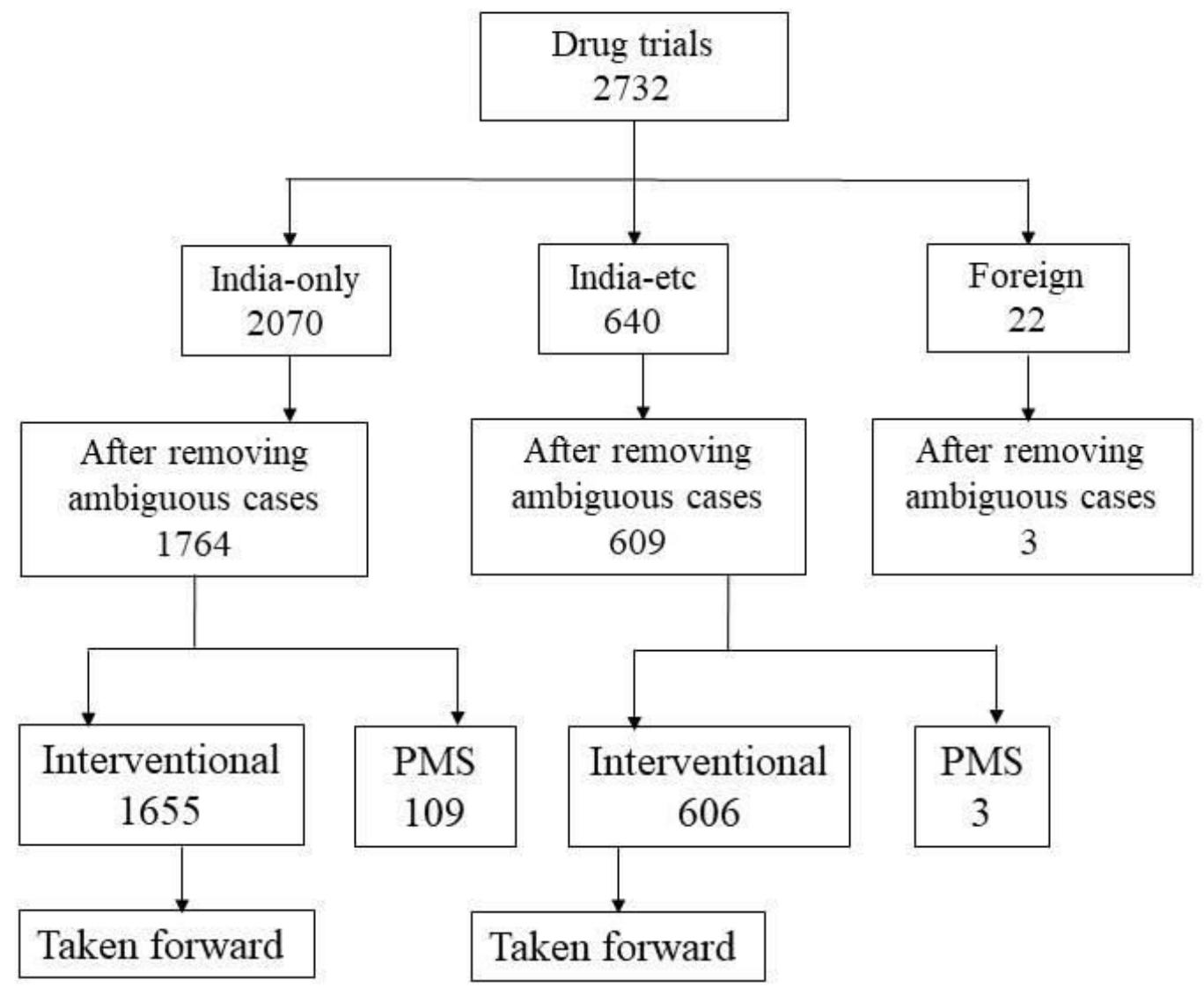

Figure 1

A flowchart of the steps taken to identify the two sets of trials chosen for this study.

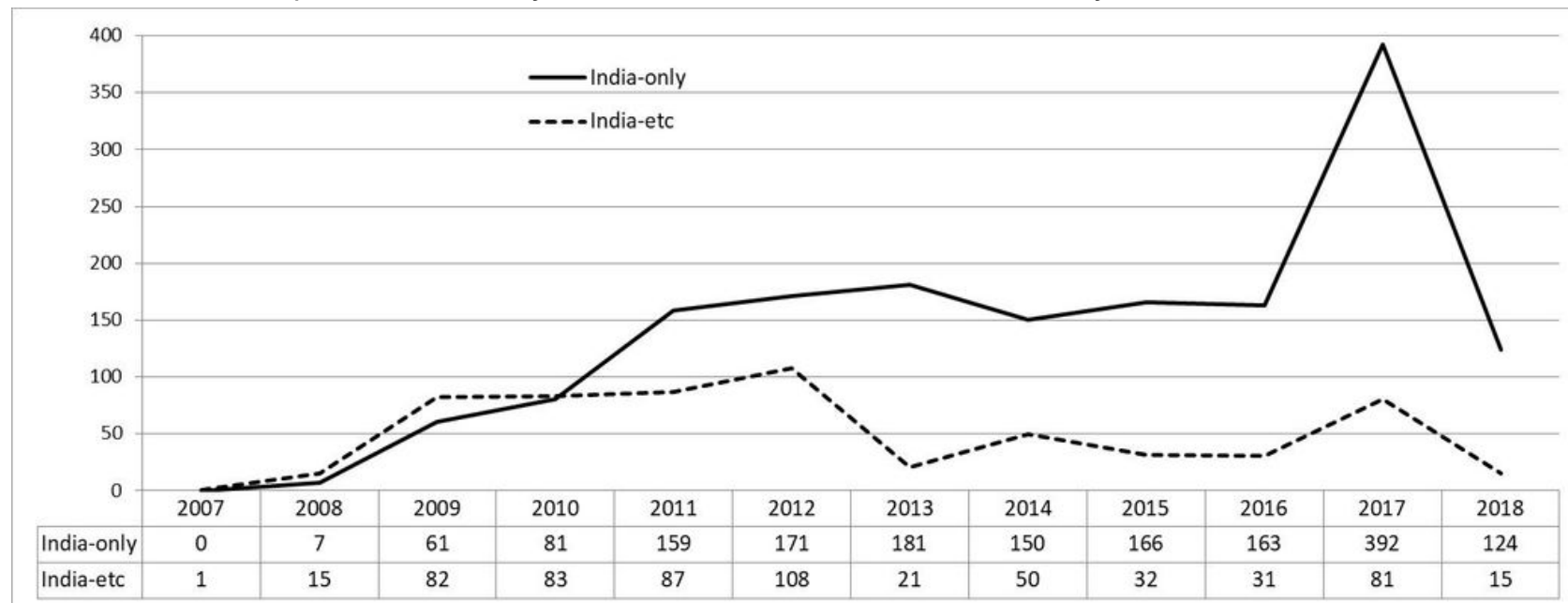

Figure 2 


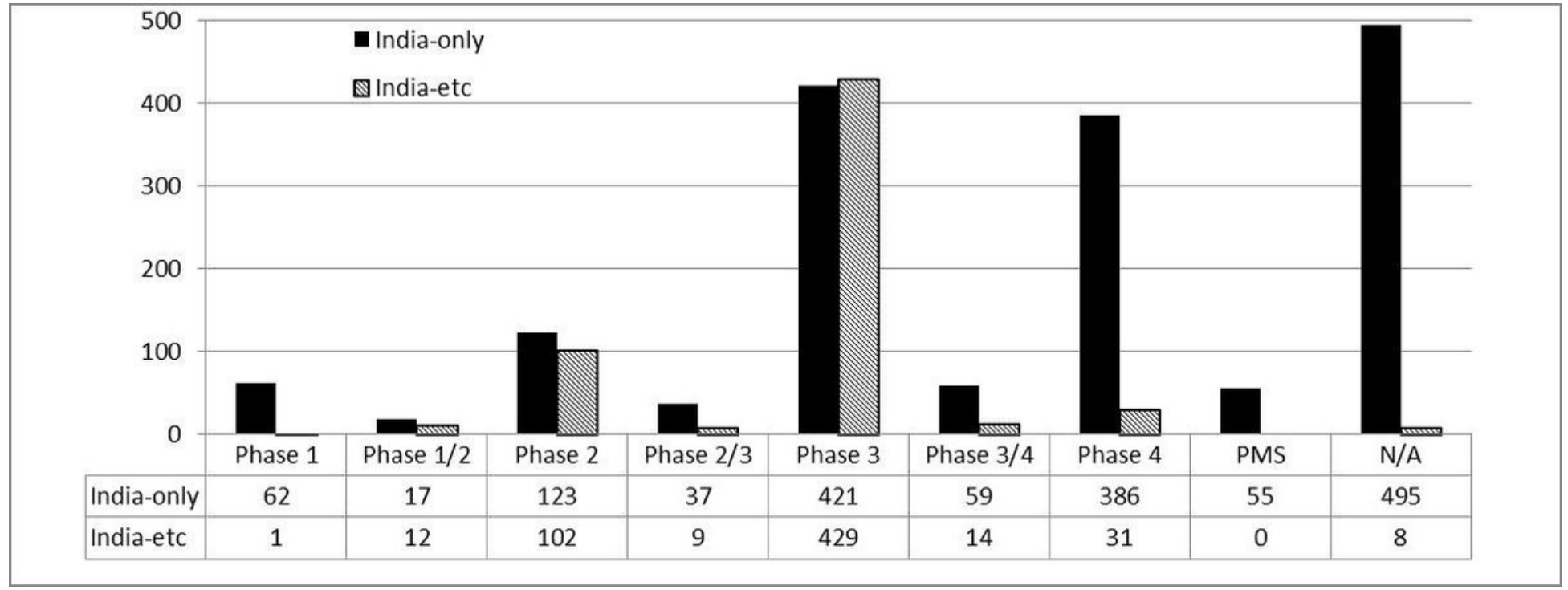

\section{Figure 3}

For the 1,655 India-only and the 606 India-etc trials, the number of trials in each phase. PMS = Post-marketing surveillance; N/A = Not available.

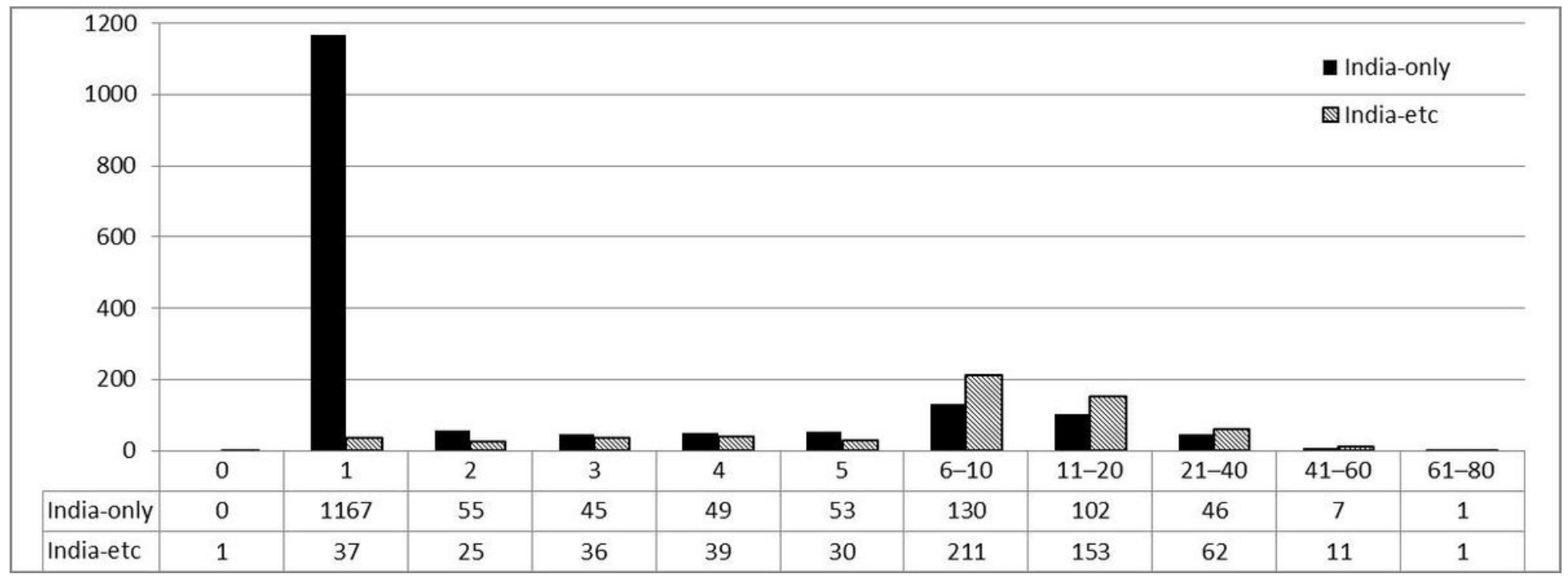

\section{Figure 4}

For the 1,655 India-only and 606 India-etc trials, the number of trials versus the number of ethics committees per trial. 


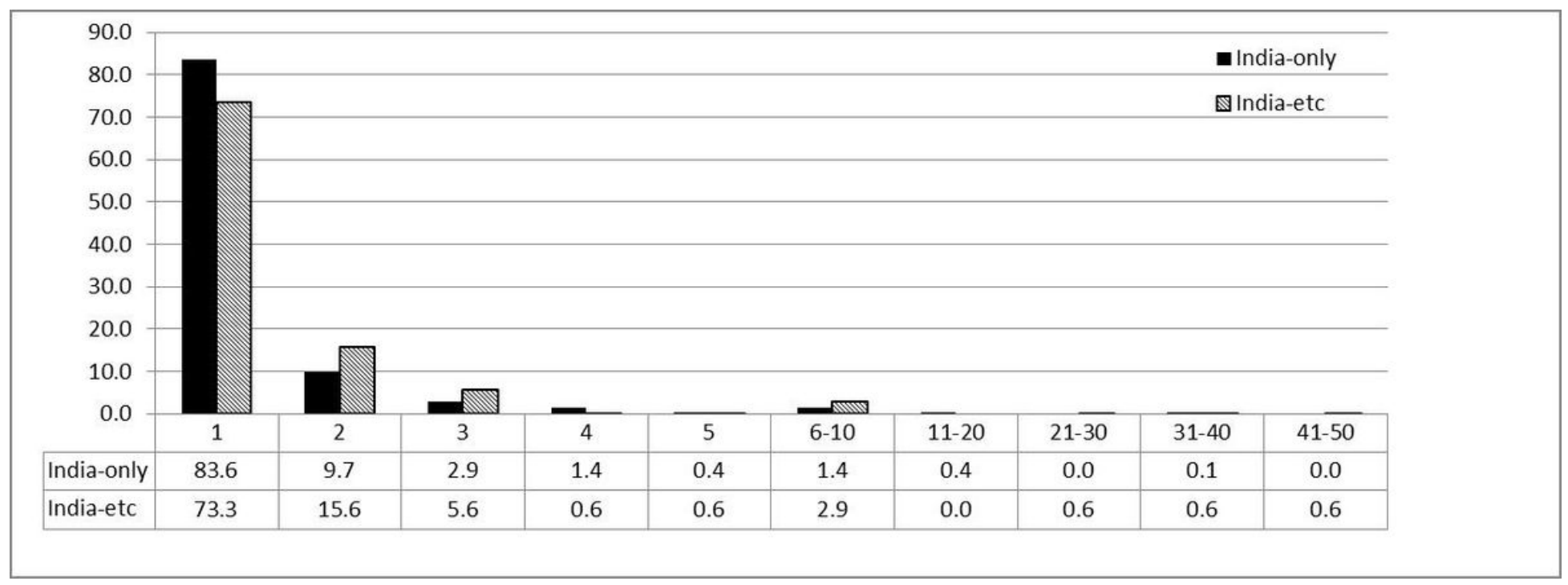

\section{Figure 5}

For the 1,655 India-only and the 606 India-etc trials, the percentage of PIs that have run different numbers of trials.

\begin{tabular}{|r|r|r|r|r|r|}
\hline & \\
\hline
\end{tabular}

\section{Figure 6}

For the 606 India-etc trials, the percentage of trials in Phases 1, 2, 3 and 4, binned for fraction of planned recruitment from India. 


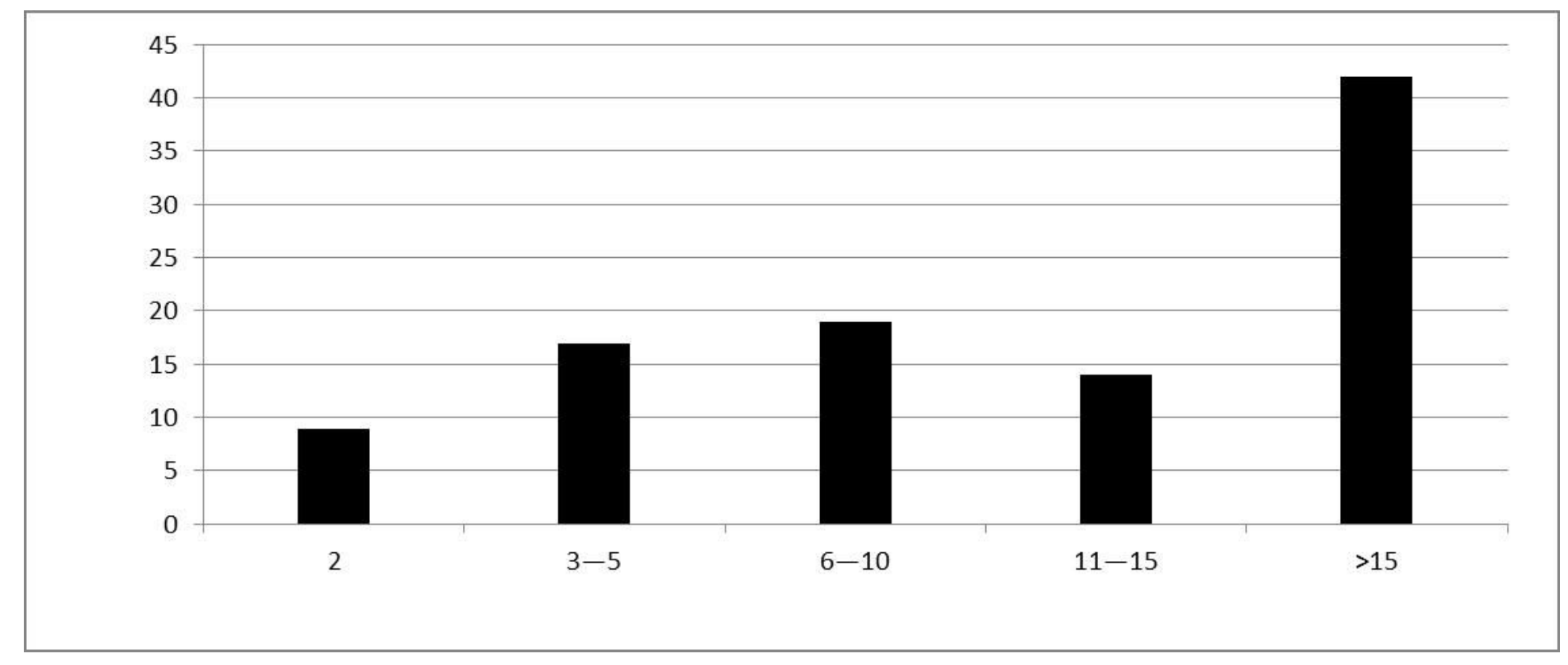

Figure 7

For the 606 India-etc trials, the percentage of trials versus the number of countries per trial.

\section{Supplementary Files}

This is a list of supplementary files associated with this preprint. Click to download.

- AdditionalFile4.doc

- AdditionalFile8.xIs

- AdditionalFile13.xls

- AdditionalFile5.xls

- AdditionalFile14.xls

- AdditionalFile3.xls

- AdditionalFile6.xls

- AdditionalFile12.xls

- AdditionalFile9.xls

- AdditionalFile10.xls

- AdditionalFile11.xls

- AdditionalFile15.xls

- AdditionalFile17.xIs

- AdditionalFile16.xls

- AdditionalFile7.xls 